\title{
HUMAN TARGET SELECTED BY THE ADVERSE INTELLIGENCE SERVICES FOR OBTAINING CLASSIFIED INFORMATION
}

\author{
Laurențiu- Leonard LĂZĂROIU \\ “Nicolae Bălcescu” Land Forces Academy Sibiu, Romania \\ lllazaroiu@yahoo.com
}

\begin{abstract}
Generally, to be competitive, the intelligence services are required, by their status itself, to constantly assess the capacity and performance and also to anticipate the behaviour of potential adversaries in achieving and maintaining a superior informational advantage.

Illegal access of adverse intelligence services to national information strategy is a well defined aim, involving carefully designed scenarios and continuous assessment, performed by specialized structures. In the economy of intelligence business, a logical condition is the selection of human intelligence sources, primarily among those whose professional duties involve access to valuable information, the disclosure of which may be established strategic advantages.

The results are often negative immediate or medium-term consequences, unpredictable, both on national security and on a proper functioning of the state.
\end{abstract}

Keywords: intelligence services, human intelligence sources, classified information, disclosure.

\section{Introduction}

It is essential to any authorized person to deal with classified information, regardless of the institution in which he operates, the existence of two personality traits combination: fidelity and loyalty to the values of the nation and to the institution which he belongs.

Often human subject associates the ideas of patriotism and justice to the nationalism, which he believes are sometimes attached to extremism, just by the presence in massmedia of the activity done by Romanian or foreign organization that increase in a certain way some patriotic feelings or values. Values listed are aspects with a general character for all population of a nation and not mandatory criteria by which people are normally judged by society. However, from the national population are selected some members of society, with special skills and personality treats, to fulfill a special social assumed role. These members of society will use sensitive information for national security, so for them is required and also is tested the existence of values such as patriotism and loyalty. These values are mandatory and could be measured during psychological specific tests.

\section{Person's eligibility for access to classified information}

When the state is unable to provide its citizens for reasons of fidelity and loyalty, as projection of efficient administration and justice, whose benefits translate into welfare, law and perspectives, there will be a major danger zone. Thus, people's vulnerabilities in front of various destabilizing trends become huge and hard to manage [1].

Interest on ideal values of the personal who access sensitive information is not a 
problem isolated to national or European regional level, but is widespread worldwide, both in democracies as well as in authoritarian. The main aim for each country rests the same, despite the fact that social life is changing during historical periods. It is represented by its nation power to protect sensitive information against disclosure to enemy.

In the United States law, a person's eligibility for access to classified information has been regulated since 1987, improved in 1995, implemented at the departmental level in 1997 and it was revised in 2005, under the title Adjucative Guidelines for Determining Eligibility for Access to Classified Information, being approved by the C.I.A. director. In an attempt to synthesize aspects considered over time in the U.S. recent history, in order to define the most important personal values according to the subject of classified information access, have resulted 13 key criteria, useful to identify the eligibility for access to classified information. The goal is to anticipate the vulnerability from the unauthorized or authorized person to provide indices on the occurrence of crime of treason, illegal disclosure of information. Such, are analyzed and evaluated these:

- loyalty to the state or nation;

- -foreign influences (family members, environment, knowledge) on personal life;

- recovery, sympathy, attraction of assets belonging to foreign state or culture;

- personal conduct;

- behaviour / sexual deviations;

- aspects of financial condition;

- alcohol / drugs;

- psychological aspects;

- criminal behaviour;

- extracurricular activities;

- the use of IT resources and online behaviour.

The criteria set listed above, by applying them in the verification of staff from relevant security institutions, are directly filters for excluding the filling of specific sensitive positions by susceptible individuals (to accidentally compromise classified information and intentionally disclose them outside the legal framework). In Romania, in general, the decision on issuance of security clearance approval or authorization to classified information access focuses on two major issues:

- unquestionable loyalty to the person;

- character, habits, relationships and discretion.

Further steps to protect information in terms of overall vulnerability of the human subject, characterized by unpredictability, are summarized under national law, under the concept of personal protection.

We can admit that in Human resource management, for achieving the goal of protection of personnel, it is necessary to take into account:

- "personal equation" single individual (temperament, personality traits, intelligence, skills, adaptability);

- functional personal motivation in carrying out their duties;

- the need for continuous training;

- availability of performance standards.

If, inside institutions and organizations, the rules are complementary constrains with cultural traditions, perpetuated as long as have rewarded behaviour benefits, value or economic benefits, among institutions which handle classified information rules were more than in any other areas onerous functions, in order to limit variability space of initiatives, actions and interactions. Through these forms of organization, institutions that handle classified information are bureaucratic institutions. In bureaucracy, the roles are clearly and precisely prescribed in the hierarchy of authorities, functions and tasks are carried out according to the rules and predefined procedures. There, information travels in writing or electronically ways, with the opportunity to preserve and archive it, so the personal submission and hierarchy are regulated to generate impersonal, efficient and equitable leadership. 
Despite all the mentioned features and related aspects, we consider that for any foreign intelligence service the interest directed to having access to classified information persons is an increased effort, in this direction competing with that effort used in identifying gaps or breach in technical systems.

The implementation of actions to be permanent creation of dependency and informative conscious human exploitation are well-defined procedural action strategies in intelligence. Unfortunately in terms of defensive view the results are often directed against national interests.

\section{Leaking of classified information}

Interesting for our research approach is the development of some capacities in order to prevent gathering information by hostile intelligence services or organizations through HUMINT sources. The fact is that the information's value that can be obtained from HUMINNT sources is dependent on the activity of HUMINT source practicing and on the level of access to classified information.

By analyzing 130 cases of treason by leaking classified information [2] statistical evaluation shows a relevant rank, targeted to major professional fields of those who have committed the crime of leaking information in favour of another state, as follows:

- military personnel or civilian employee in the military, 34 cases;

- employees from intelligence structures, 26 cases;

- scientists involved in research projects, 23 cases;

- government officials, diplomats and politicians, 21 cases;

- businessmen, 12 cases;

- persons involved in terrorist activities, 6 cases;

- I.T. specialists, 5 cases;

By presenting this ranking we not propose drawing some conclusions on the incidence of crime, in conjunction with particular aspects of the areas of listed activities, but founding a directly proportional relationship between value and volume of handled classified information in certain fields. It is basically a ranking of areas of interest to intelligence services in general, but also to counterintelligence structures, as a defensive action.

We believe that, with decision makers to the social domains (economic, political, military, administrative etc.), those who have access to information of the highest strategic level (some of them providing to the others received product information) are officials from intelligence institutions. The fact is, generally expressed, that the one who is in charge with the collection and processing of information can more easily use its unauthorized distribution, by the simple reasoning that this person has at a proper moment of time the possession of valuable information.

At the national level, analyzing the content of folders in the background investigation of archived Security files, we identify a category of intelligence officers that, during the communist period, their actions have undermined national security, being accused or in charge of treason by leaking secret information to another State than national one who they belongs. We call them defectors, intelligence officers in an abroad mission, who refuse to return to the country [3].

The literature on the history of espionage and counterespionage techniques presents two types of defectors, turncoats, intelligence personnel who in one or another manner managed, in an extremely way, sensitive documents:

- turncoats defectors, who leave their country for political, ideological or economic to provide information to an enemy power;

- active turncoats defectors, who accept to remain in their country, but acts as a "mole" for the opposite intelligence service;

In the intelligence activity, we identify two 
types of defectors, recovered after their role on the protection of classified information (by intoxication adverse services with false data and information) or about the disclosure of sensitive information and compromise documents [4].

- bad defectors- traitors who disclose state authentic secrets to opponents;

- good defectors- who continue to serve their country under cover of traitors, intoxicating opposite intelligence services with information processed in order to product wrong or false information;

In any of these two cases the risk has a higher level and the chance to discover the real intention is to big for perpetuating this kind of actions.

\section{Conclusions}

Researching, both in terms of statistical and also from the perspective of the historical archives of intelligence services, the pressure to provide illegal information, other than public (classified information), will be concentrated in certain professional categories: from military employees, intelligence structures personnel, government employees, to business and IT specialists.

The biggest goal of intelligence structures and especially of counterintelligence component remains to identify and counteract the unauthorized transmission of classified information. For this purpose, the implementation and ongoing monitoring, used to identify eligibility criteria access to classified information, coupled with efforts focusing on personally identifiable information, which according to analysis shows the highest incidence of crime, are mandatory preventive requirements for specialized departmental structures.

The recourse to the interpretation of the security incident, both nationally level and in terms of NATO and EU, along with aspects of sentencing legal criminal acts and analyses measures for personnel recruitment were intended to emphasize that treason, by leaking classified information, represents risks with a deterrent role oriented to person who commits this crime. Moreover, the act is the result of individual internal issues (mental, motivational, attitudinal, etc.) transposed in attitudes and behaviour.

\section{References}

[1] Cristian Tabără, Cât ne costă deficitul de stimă de sine, Revista Intelligence, nr.16, 2009, pp.9-11

[2] George Cristian Maior, Spionii cine sunt, ce fac, București, Ed.RAO, 2013

[3] Constantin Troncotă, Enigma defectorilor transfugi din fostul bloc estic comunist din Europa, București 2009, pp.22-25

[3] Ibidem 